\title{
Eco-electric energy generator system using human exercise activities
}

\author{
Frans Setya Prabowo ${ }^{1}$, Porman Pangaribuan ${ }^{1, *}$, and Denny Darlis ${ }^{2}$ \\ ${ }^{1}$ Telkom University, School of Electrical Engineering, Jl. Telekomunikasi, Bandung, Indonesia \\ ${ }^{2}$ Telkom University, Diploma of Telecommunication Engineering, Jl. Telekomunikasi, Bandung, Indonesia
}

\begin{abstract}
Today human need for electrical energy is very high. For that we need to find an alternative power plant renewable energy, especially environmentally friendly. One type of an environmenttally friendly power plant is a generator which is harnessing human-generated energy when exercising by using a static bike. This equipment is used on average 6 hours per day at 5.00-8.00 hours and 17:00 to 20:00 hours. In this research, a power plant system by utilizing human motion exercising from wheel rotary mechanics, generators, BCU (Battery Control Unit), and battery will be designed. The rider can see from the LCD when the battery condition is full, the battery is charge, the battery does not get energy from the generator, inverter on, inverter off, battery voltage and generator voltage. At the testing stage, 14 participants cycling for 15 minutes produced electrical energy on average of 594 Joules, with an age range of 20-23 years old. The resulting energy can turn on the light 3 Watt between $160-251$ seconds or 198 seconds on average. When accumulated 14 cycled samples with 15 minutes each (total 210 minutes) can generate 8313 Joule electric energy and can turn on 3 Watt lamp for 46 minutes 11 seconds.
\end{abstract}

\section{Introduction}

The human need for electrical energy today is very high. Most of this need is supplied by power plants using fossil fuel that is not environmentally friendly. According to various data such as the United Nations Framework Convention on Climate Change (UNFCCC) in Bali presents the needs of developing countries to get the transfer of environmentally friendly technologies for contributing to the success of reducing emissions and preventing global warming. One form of eco-friendly power plant is harnessing human-generated energy when exercise using static bicycle [1], [2].

This system is used for 6 hours average per day at 5.00 to 8.00 am and 05:00 to 08:00 pm. The average cycling activities generates 75 watts / hour, or 450 watts in 6 hours [1]-[4]. In this research, a system that include of mechanical wheel rotation, DC generator, BCU (Battery Control Unit), and battery has been designed. This system is also equipped with LCD, so that users can know the condition of full battery, batteries are being filled, batteries do not get energy from the generator, inverter condition on / off, battery voltage and output voltage generator.

\section{System implementation}

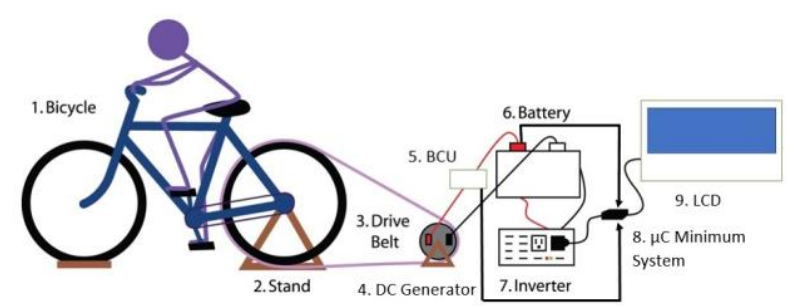

Fig. 1. System Configuration [5]-[7].

The eco-electric energy generator was implemented using system configuration show on Fig.1. The specifications of the each part, respectively:

- Chain is the link between the stroke and the rear wheel, and drive belt is the link between the rear wheel and the DC motor.

- Generator produces voltages between 10 volts to 60 volts.

- Rotary encoder and optocopler sensor to show the $\mathrm{ADC}$ and rotational speed.

- Battery control unit as a safety and limit voltage into the battery.

- Battery for power storage generated by $35 \mathrm{Ah} 12$ volt and 60Ah 12 Volt.

- Minimum system to control and adjust speed, voltage, ADC.

- $\quad \mathrm{AC}$ and DC lamps as loads used.

- LCD to display the voltage, speed, power obtained.

\footnotetext{
* Corresponding author: porman@telkomuniversity.ac.id
} 


\subsection{System details}

One form of eco-friendly power plant is to utilize the energy produced by humans when exercise using a static bike. When bicycle is pedalled, the wheels will rotate and generate DC electric voltage in the coil according to the law of electric motion force and will output current if loaded.

Fig. 2. Static Bicycle Generator Block Diagram.

\subsection{Chain mounting}

The chain function is as a player that moves power from the pedal to the wheel then move the tire. The position of the pedal chain is on the right and the position of the motor chain is on the left of the rider. The design of the chain is as follows:

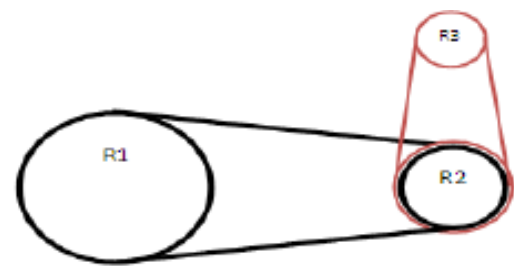

Fig. 3. Bike chain design drawing.

With value of radius of holder of chains equal to: $\mathrm{R} 1$ : $\mathrm{r}=10 \mathrm{~cm} ; \mathrm{R} 2: \mathrm{r}=5.5 \mathrm{~cm} ; \mathrm{R} 3: \mathrm{r}=1.8 \mathrm{~cm}$

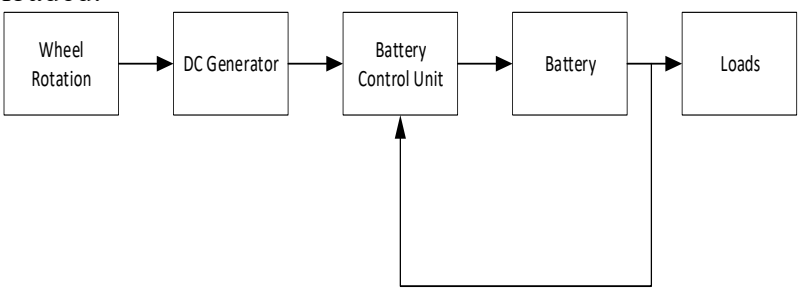

\subsection{Battery control unit}

Battery control unit serves for the safety and limit the voltage that goes into the battery. The circuit schematic for the BCU showed on Fig.4.

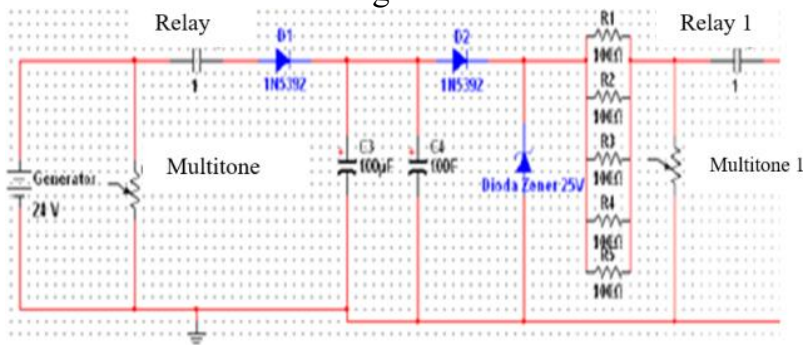

Fig. 4. Battery control unit.

Resistor paralleled with the purpose of current divider, $100 \Omega 10$ Watt resistor, and $\mathrm{R}$ parallel value $=$ $100 \Omega / / 100 \Omega / / 100 \Omega / / 100 \Omega / / 100 \Omega=20 \Omega$. Relays function as On-Off switches, under the EKE brand. BCU uses two relays, the relay I works to connect between the generator and the battery with the initial closed / NC (normally close) condition, the closed switch means charging the battery. While relay II serves to connect between the battery with the load, the initial condition of the switch is open / NO (normally open), the switch is open if the battery voltage is less than $10.5 \mathrm{~V}$, the switch is closed if the battery voltage between $10.5 \mathrm{v}-13.8 \mathrm{~V}$ good battery condition

\subsection{Display circuit}

To display some variables need to be monitored by the user the system used LCD display connected to the minimum circuit microcontroller. This circuit uses ATMEGA8535 made by ATMEL with configuration as shown in figure 4.

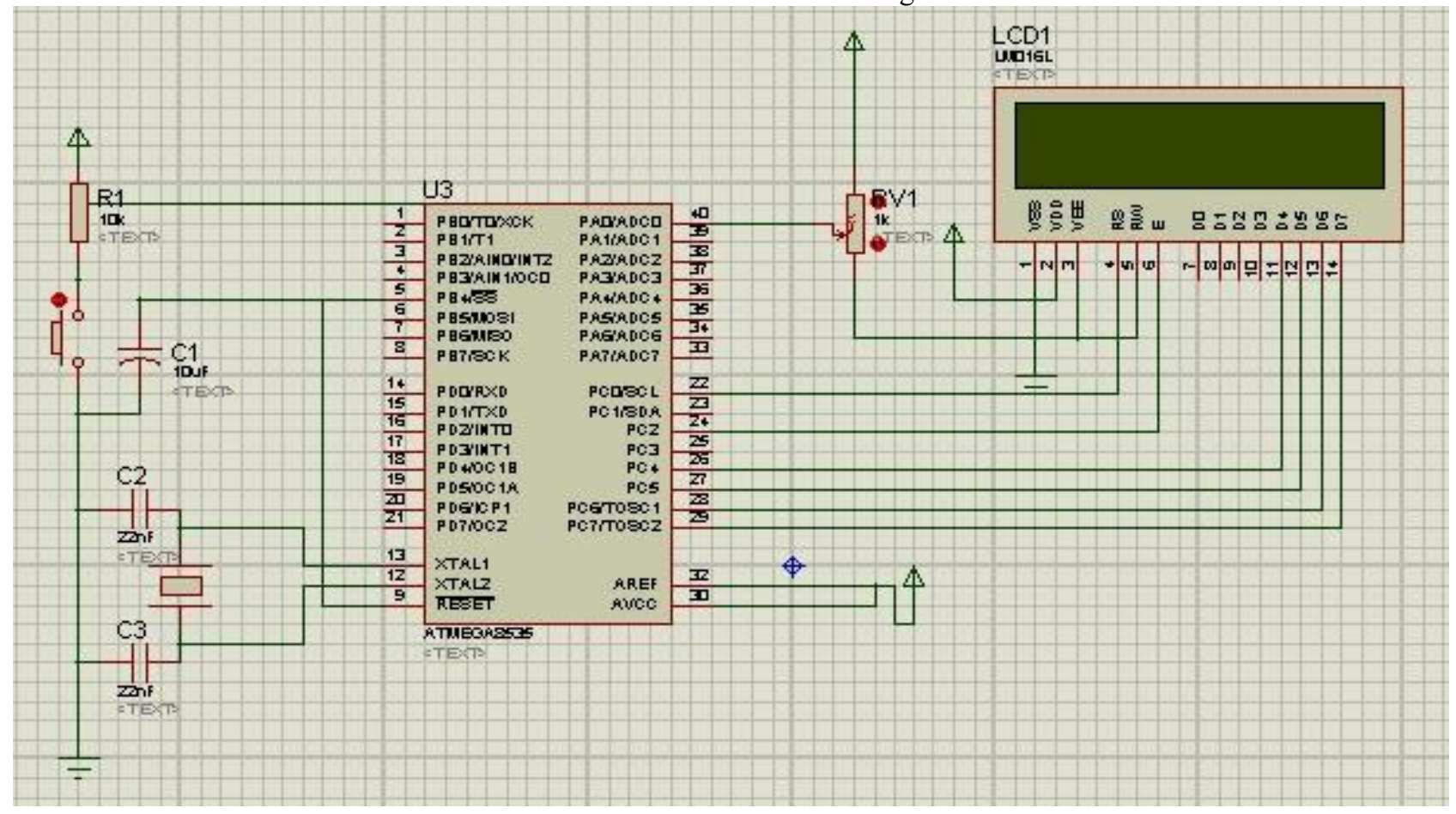

Fig. 5. LCD circuit connected to ATMEGA8535 minimum system. 


\section{Results and discussion}

\subsection{Measurement of battery voltage}

Measurement of battery voltage before being given a load of $12.22 \mathrm{~V}$ and if given the load voltage to $11.66 \mathrm{~V}$.

Measured battery acid condition using Hydrometer, Normal batteries have a specific gravity of $1.27-1.29 \mathrm{~kg}$ $/ \mathrm{cm} 3$. If below it then must be in charge replaced or replaced with new battery acid.

\subsection{Battery charge and discharge test (charge - discharge)}

\subsubsection{Circumstances if charge power discharge, using power supply}

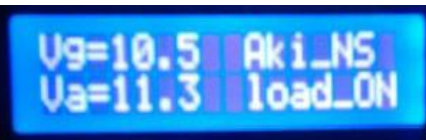

Fig. 6. LCD display when battery does not exist source and battery can discharge.

\subsubsection{Circumstances if charging power $=$ discharge, using power supply}

\section{Ug=12.1 Aki_Isi $\mathrm{Va}=11.4$ load_OK}

Fig. 7. LCD display when battery charge and the battery can discharge.

\subsubsection{Circumstances if charging power < discharge, using power supply}

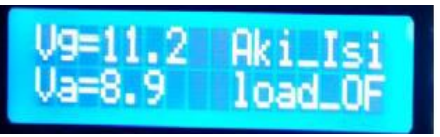

Fig. 8. LCD display when the battery charge and the battery cannot discharge.

\subsection{Calculated and measurements of energy generated}

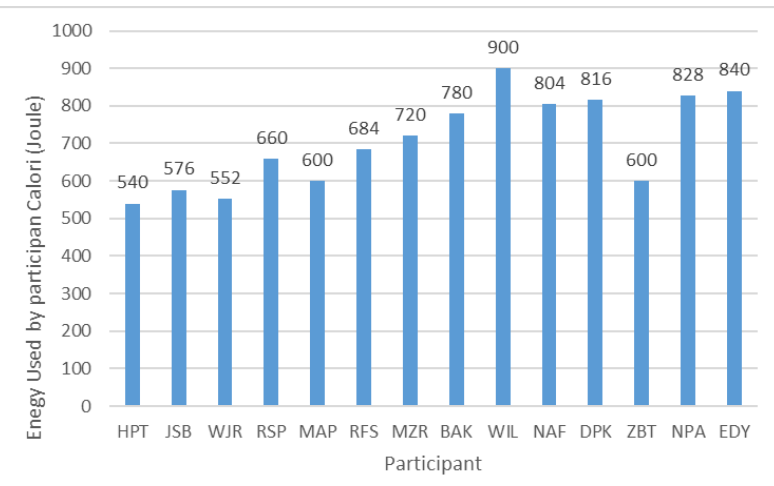

Fig. 9. Energy calculation for 14 participants.

\footnotetext{
*orresponding author: porman $@$ telkomuniversity.ac.id
}

The calculated energy used by 14 participants when cycling over static bike for 15 minutes are shown on Fig.9. As we can see the weight of each participants denote the energy generated.

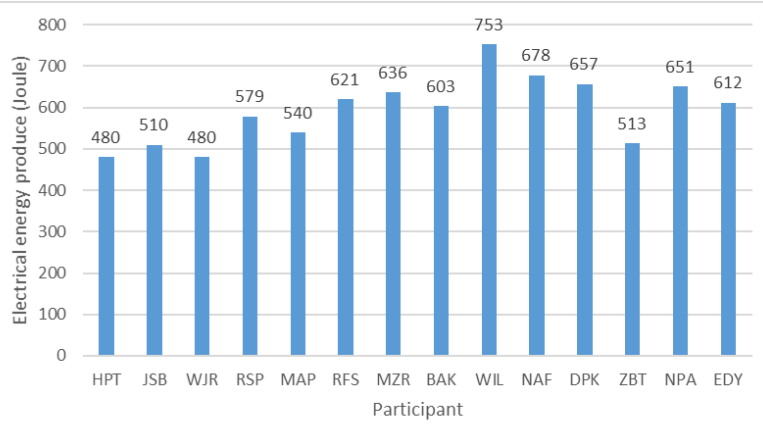

Fig. 10. Electrical energy produced from 14 participants.

Fig.10 show the generated energy from by 14 participants when cycling over static bike for 15 minutes. These energy were used to turn on a $3 \mathrm{~W}$ light bulb between $160-251$ seconds or 198 seconds on average.

\section{Conclusions}

Based on the testing results, the energy calculated for 14 people when cycling a static bike can generate 594 Joules and this energy can be use to turn a 3 Watt light bulb between $160-251$ seconds or 198 seconds on average. We can generate more power if we provide more static bike and ride for more time. This system can be implemented as an Eco-Electric Energy Generator System Using Human Exercise Activities.

Authors would like to thank School of Engineering and School of Applied Sciences, Telkom University for supporting materials and facilities in this research.

\section{References}

1. T. Gibson, IEEE Spectrum, (2011).

2. R. Z. Arndt, Pedal Power! How to Build a Bike Generator (POPULAR MECHANICS, 2014).

3. P. Kadi and S. Kulkarni, "Hybrid Powered Electric Bicycle," vol. 4, no. 5, pp. 1017-1020, 2016.

4. G. Laštovi, "Generating Electricity through Pedal Power," vol. 3, no. 2, pp. 16-29, 2017.

5. B. Pelz and J. Feiereisen, "Bicycle Powered Generator for the University Farm," (2010).

6. Ş. Mocanu, A. Ungureanu, and R. Varbanescu, Asia Pacific J. Multidiscip. Res., 3, (2015).

7. M. C. Hsieh and D. K. Jair, Energy Environ. Res., 4, (2014). 